\title{
Las candidaturas
}

independientes en las

elecciones de 2015

en México. Límites

legales, éxitos electorales

y participación ciudadana*

/ Independent Candidacies

in the Elections of 2015

in Mexico. Legal Limits,

Electoral Successes and

Citizen Participation

* Recibido: 7 de enero de 2015. Aceptado: 26 de febrero de 2015.

Tla-MelauA, revista de Ciencias Sociales. Facultad de Derecho y Ciencias Sociales. Benemérita Universidad Autónoma de Puebla, México / ISsN: 1870-6916 / Nueva Época, Año 10, No 40, abril/septiembre 2016, pp. 60-86. 


\section{RESUMEN}

Este artículo analiza las principales desigualdades normativas y fácticas que enfrentaron las candidaturas independientes en materia de financiamiento y acceso a medios durante el proceso electoral 2014-2015 en México. Además, se describe su desarrollo durante dicho proceso. Por primera vez en la historia de nuestro país, seis candidatos independientes ganaron elecciones: una gubernatura, tres alcaldías y dos diputaciones. A nivel federal, los independientes se posicionaron como la tercera fuerza política en los veinte distritos electorales donde participaron. A excepción de Jaime Rodríguez "El Bronco", en Nuevo León, los candidatos independientes no aumentaron el porcentaje de participación ciudadana, si se compara este porcentaje con el de la elección inmediata interior. Salvo José Kumamoto en Zapopan, Jalisco, y César A. Valdés en García, Nuevo León, los cinco candidatos independientes militaron en partidos políticos, lo que hace cuestionable su independencia.

\section{PALABRAS CLAVE}

Candidaturas independientes, éxitos electorales, inequidad electoral, participación ciudadana, elecciones 2015.
A B S T R A C T

This article analyzes the main normative and factual inequalities that independent candidacies faced in financing and access to the media during the 2014-2015 electoral process in Mexico. In addition, their development during this process is described.

For the first time in the history of our country, six independent candidates won elections: one governorship, three mayors and two council members.

At the federal level, the independents positioned themselves as the third political force in the 20 electoral districts where they participated.

With the exception of Jaime Rodriguez "Bronco", in Nuevo León, independent candidates did not increase the percentage of citizen participation if this percentage is compared to that of the immediate interior election.

Excluding José Kumamoto in Zapopan, Jalisco, and Cesar A. Valdés in Garcia, Nuevo Leon, the five independent candidates served in political parties, which makes their independence questionable.

\section{KEYWORDS}

Independent Candidates, Electoral Successes, Electoral Inequality, Citizen Participation, 2015 Elections.

\footnotetext{
* Profesor investigador en la Facultad de Derecho y Ciencias Sociales de la Benemérita Universidad Autónoma de Puebla, México. (oscar_lagunes@hotmail.com)

** Profesor investigador en la Facultad de Derecho y Ciencias Sociales de la Benemérita Universidad Autónoma de Puebla, México. (parellanes3@hotmail.com)
} 

dentes histórico-jurídicos / 4. El marco normativo electoral / 5. El financiamiento público y privado / 6. Los espacios en radio y televisión / 7. Los candidatos independientes en el proceso electoral 2014-2015 / 8. Los seis triunfos independientes / 9. Conclusiones

\section{INTRODUCCIÓN}

Las candidaturas independientes fueron la gran novedad en el pasado proceso electoral 2014-205. El análisis de la normatividad electoral y de los candidatos independientes que obtuvieron el triunfo en las elecciones del 7 de junio del 2015, abona elementos de reflexión al debate sobre la "independencia" en relación con los partidos políticos. En esta investigación se indaga si las candidaturas independientes activaron la participación ciudadana. Este ha sido el supuesto de las iniciativas que se presentaron en la LX Legislatura de la Cámara de Diputados del Congreso de la Unión para introducir la nueva figura. ${ }^{1}$ Además, se ha supuesto que las reglas del juego fomentan la equidad entre las candidaturas de partido e independientes. Finalmente, se identifican las restricciones legales y fácticas que enfrentaron los candidatos sin partido. ${ }^{2}$

El capítulo está estructurado en nueve partes. En las primeras cinco, se hace un recuento histórico de su evolución, se analiza la normatividad que las rige y se desarrollan aspectos teóricos. En las cuatro partes restantes, se describe el desarrollo de las candidaturas independientes durante el proceso electoral, particularmente de los seis candidatos independientes que ganaron las elecciones.

Reflexionaremos sobre las reformas requeridas para equilibrar la competencia electoral entre las candidaturas de partido y las independientes. La metodología mezcla el análisis documental y el normativo con la revisión de las estadísticas sobre la elección de 2015. El contraste entre teorías, normatividad y casos concretos, propio de los métodos deductivo e inductivo, coadyuvó a la detección de las deficiencias y los avances en el desarrollo de la nueva figura en nuestro país.

\footnotetext{
${ }^{1}$ Cfr. Gamboa Montejano, Claudia, Candidaturas independientes. "Estudio Conceptual, de antecedentes, Furisprudencia, Iniciativas presentadas en la LX Legislatura y LXI Legislaturas, de Derecho Comparado y Opiniones especializadas", México, Congreso de la Unión, p. 17. [Consulta: 15 de septiembre, 2016]. Disponible en: http://www. diputados.gob.mx/sedia/sia/spi/SAPI-ISS-09-11.pdf

${ }^{2}$ En esta investigación se manejan como sinónimos "candidatos independientes", "candidatos sin partido" y "los independientes".
} 


\section{ASPECTOS TEÓRICOS}

Es indispensable definir primero qué es un candidato, para delimitar qué es una candidatura independiente. Por candidato se entiende "aquellas personas que habiendo cumplido ciertos requisitos, son propuestas a un determinado cargo público, los cuales ostentan diferentes programas políticos y podrán ser elegidos mediante sufragio universal". ${ }^{3}$ En cambio, las candidaturas independientes son "la nominación para ocupar un cargo electivo, cuyo rasgo peculiar y sobresaliente consiste en que tal oferta política se realiza sin el concurso, ni principal ni complementario, de un partido político". "No se les debe confundir con los candidatos no registrados. Estos últimos "son aquellos inscritos por los electorales en los espacios en blanco establecidos en las boletas electorales". ${ }^{5}$

Las candidaturas son un elemento fundamental de la representación política y, a la vez, un mecanismo que permite la realización de los principales derechos políticos de los ciudadanos. Hacen posible la representación política mediante el acceso al voto pasivo y activo, ambos derechos centrales en un sistema democrático. Aunque el pueblo sea la sede, el origen y el fundamento del poder, éste se ejerce a través de representantes e instituciones. Las instituciones permiten que el poder se haga empírico, es decir, que aparezca en el campo político como fenómeno, dada la imposibilidad fáctica de que el pueblo lo ejerza directamente. ${ }^{6}$ En esta línea, "las candidaturas son un derecho político y una condición necesaria para la representación, de modo que si las candidaturas forman parte de los derechos inalienables de los ciudadanos, las candidaturas independientes también lo son, puesto que su origen es el mismo".7

En las democracias modernas, la representación recae en los partidos políticos. Estos tienen un doble mandato: con los electores y con sus partidos. Este último es el que prevalece. "En la medida en que crece la democracia de masas", la mediación de los partidos políticos se vuelve indispensable en los procesos representativos. ${ }^{8}$ Sin embargo, como señala Sartori, el sistema democrático representativo tiene dos fases: la relación elector-partido y la relación partido-representantes, con predominio de la primera. Por un

\footnotetext{
${ }^{3}$ Hernández Olmos, Mariana, La importancia de las candidaturas independientes, México, Tribunal Electoral del Poder Judicial de la Federación, 2012, p. 13.

${ }^{4}$ Zovatto, Daniel, "Regulación jurídica de los partidos políticos en América Latina. Lectura regional comparada", en Daniel Zovatto (coord.), Regulación jurídica de los partidos políticos en América Latina, México, UNAM - IDEA, 2008, pp. 137-138.

${ }^{5}$ González Oropeza, Manuel, "Candidaturas independientes", Ensayos, p. 46. [Consulta: 15 de septiembre de 2016]. Disponible en http://historico.juridicas.unam.mx/publica/librev/rev/sufragio/cont/4/ ens/ens7.pdf

${ }^{6}$ Cfr. Dussel, Enrique, 20 tesis de política, México, Siglo XXI - Crefal, 2010, p. 30.

${ }^{7}$ Hernández Olmos, Mariana, op. cit., p. 15.

${ }^{8}$ Cfr. Sartori, Giovanni, Elementos de teoría politica, Madrid, Alianza, 2012, p. 274.
} 
lado, los electores escogen al partido; por el otro, los electos son elegidos por los partidos. ${ }^{9}$ Es un sistema en el que los partidos políticos eligen a los representantes; el electorado se limita a elegirlos de una lista de candidatos previamente definida. Esto ha ocasionado que en la actualidad la sociedad mexicana no se sienta representada por la clase gobernante ni confie en los partidos políticos. ${ }^{10}$

De acuerdo con Colomer, la democracia es el "gobierno de muchos en favor de sus intereses comunes", ${ }^{11}$ ello implicaría que en un sistema de gobierno con división de poderes, la utilidad social podría ser mayor sólo si los ganadores pueden satisfacer "diferentes grupos de preferencias de los votantes". ${ }^{12}$ Desde esta perspectiva, las candidaturas independientes se sumarían al grupo de los ganadores para satisfacer las preferencias de aquellos votantes que no se identifican con los partidos políticos. Es más, podrían corregir las deficiencias del actual sistema de representación, que hasta hace poco sólo concedía a los partidos políticos el derecho de proponer candidaturas. Es socialmente útil la incorporación de las candidaturas independientes, pues son una alternativa al sistema de partidos y un canal de participación directa a los cargos de elección popular.

En cambio, hay que tomar en cuenta que todo el sistema político electoral mexicano se ha construido durante más de tres décadas en función de los partidos políticos, razón por la cual es difícil implementar las candidaturas independientes dentro de ese sistema, puesto que éstas no son comparables con los partidos políticos en virtud de su naturaleza y sus fines. ${ }^{13}$ Ello implicaría que en la legislación referente a las candidaturas independientes, aún más en la práctica, se den diferencias en favor de las candidaturas de partido debido a su enraizamiento histórico y normativo.

El sistema representativo se caracteriza por la relación entre el "principal" (el electorado) y el "agente" (representantes electos). Estos últimos aventajan al primero en términos de información y el voto es muy limitado como mecanismo de control y sanción de los gobernantes electos. ${ }^{14}$ Existen incentivos que inducen a los representantes a incumplir el mandato de los electores,

\footnotetext{
${ }^{9}$ Cfr. Sartori, Giovanni, op. cit., p. 275.

${ }^{10}$ En México dos terceras partes de la población no se sienten representadas por sus gobernantes y desconfian profundamente de los partidos políticos. Cfr. Nateras Martínez, Eduardo, Representación Política en México, Tesis para obtener el grado de licenciado en ciencias políticas, México, Instituto Tecnológico Autónomo de México, 2014, p. 2.

${ }^{11}$ Colomer, Joseph, Instituciones politicas, Barcelona, Ariel, 2007, p. 16.

${ }^{12}$ Ibidem, p. 246.

${ }^{13}$ Cfr. Arsuaga Montoya, Rosalba, "Candidaturas independientes en proceso federal y local 2014-2015: principales derechos y prerrogativas en las campañas, fiscalización y jornada electoral”, pp. 2-3. [Consulta: 17 de septiembre, 2016]. Disponible en http://portales.te.gob.mx/ccje/sites/default/files/DelaPeza2016-1.pdf

${ }^{14}$ Cfr. Przeworski, Adam, Stokes, Susan y Manin, Bernard, Democracy, Accountabilty and representation, Cambridge, Cambridge University Press, 1999.
} 
pues desde su posición de ventaja buscan satisfacer intereses privados. Sin embargo, como señala Pitkin, "un gobierno es representativo cuando sus acciones satisfacen del mejor modo posible los intereses ciudadanos". ${ }^{15} \mathrm{El}$ problema es que en la práctica los gobiernos representativos no representan los intereses ciudadanos, no se hacen responsables de sus decisiones. Esto es opuesto al sentido original de la democracia, entendida a menudo "como la forma de Estado en donde el gobierno surge o proviene del pueblo (de la mayoría), se ejerce por el propio pueblo y en su beneficio e interés". ${ }^{16}$ Para que "la representación" sea democrática, según Przeworsky, es necesario que se le añada la "responsibidad": "un gobierno es responsivo si adopta políticas que son señaladas como las preferidas de los ciudadanos" ${ }^{17}$

En este sentido, nuestro país ha dado un paso hacia una democracia representativa responsiva al instaurar las candidaturas independientes. Estas surgen a raíz de las deficiencias del sistema representativo tradicional, que hasta hace poco se había basado exclusivamente en los partidos políticos para la postulación de candidaturas a puestos de elección popular. No obstante, la burocratización que actualmente padece el sistema de partidos, el alejamiento respecto a los ciudadanos ${ }^{18}$ y la corrupción originaron esta nueva figura legal que añade un cariz de democracia directa a la democracia representativa. ${ }^{19}$

De acuerdo con Brancati, la única característica común a todos los candidatos independientes es que no cuentan con afiliación partidista. Empero, entre ellos existen algunas diferencias. Están, por ejemplo, los political outsiders, que no disponen de experiencia previa en el gobierno; tal posición les permite presentarse como los que acabarán con la corrupción del gobierno. Los political insiders, en cambio, cuentan con experiencia previa en el gobierno y tienen trayectoria de militancia en los partidos políticos. "Muchos se separaron de sus partidos a causa de disputas sobre la dirección de éstos, conflictos personales con otros miembros de partido, o por el fracaso para ganar un lugar en la lista de candidatos de sus partidos." 20

\footnotetext{
${ }^{15}$ Poom Medina, Juan y Lugo Sau, Javier Alejandro, "Representación política y candidatos independientes: el caso de Sonora", en Oscar Nicasio Lagunes López (coord.), Los nuevos dilemas de la democracia en México, libro en prensa, p. 150.

${ }^{16}$ Santiago Campos, Gonzalo, "Las candidaturas independientes en México", Revista Derecho del Estado, núm. 33, julio-diciembre, 2014, pp. 66-67.

${ }^{17}$ Przeworski, Adam, Stokes, Susan y Manin, Bernard, op. cit., p. 8.

${ }^{18}$ Aunque los partidos políticos siguen siendo el núcleo del sistema electoral en los países democráticos, en algunos países latinoamericanos, incluido México, los partidos políticos tienen un nivel de confianza ciudadana baja. Cfr. Palazuelos Covarrubias, Israel, "La desconfianza en los partidos políticos y la percepción ciudadana de desempeño gubernamental: México ante América Latina", Revista Mexicana de Análisis Político y Administración Pública, vol. 1, núm. 1, enero-junio, 2012, p. 91.

${ }^{19}$ Cfr. Valdez, Ricardo, Las candidaturas independientes en México: condiciones de competencia y alcances, tesis para obtener el grado de maestría en Estudios Sociales, México, Universidad Autónoma Metropolitana, Unidad Iztapalapa, 2014, p. 27.

${ }^{20}$ Brancati, Dawn, "Winning Alone: The Electoral Fate of Independent Candidates Worldwide", The Fournal of Politics, vol. 70, núm. 3, julio 2008, p. 650
} 
Para este mismo autor, "la variación de la fuerza electoral de los candidatos independientes depende de tres elementos: los requerimientos legales de acceso al voto, las normas de asignación de escaños y la edad del sistema electoral". En este sentido, Brancati considera que "los requisitos para competir como independiente son más exigentes que para los partidos políticos”. Además, explica que los sistemas electorales basados en el principio de representación proporcional "incrementan la fuerza electoral de los candidatos independientes". Esto dado que los escaños se asignan de acuerdo con el porcentaje de votación obtenida en una elección; mientras que los que están basados en la regla de mayoría favorecen a los grandes partidos en detrimento de las candidaturas independientes, "por la misma razón que reducen la vitalidad de los pequeños partidos". ${ }^{21}$ Por otro lado, durante las transiciones democráticas, "los votantes tienen incentivos para votar por los independientes", toda vez que "el partidismo tiende a ser bajo en estos periodos". ${ }^{22}$

\section{ANTECEDENTES HISTÓRICO-JURÍDICOS}

Las candidaturas independientes fueron la regla de oro durante el siglo XIX, pues la teoría constitucional del siglo XVIII y XIX era opuesta a la idea de los partidos políticos. Éstos tenían intereses egoístas contrarios al interés general. La Constitución Política de los Estados Unidos Mexicanos reconocía el derecho a ser votado sólo a ciudadanos individuales. Las candidaturas independientes estuvieron vigentes durante buena parte del siglo XIX, pero en 1946 se sustituyeron al instaurarse el régimen de los partidos políticos, considerados entonces como los únicos canales legales para postular candidaturas a los cargos de elección popular. ${ }^{23}$ Dado que las candidaturas independientes no estaban prohibidas en la Constitución, sino sólo en las leyes secundarias, el legislador de Yucatán las aprobó a nivel local en el año 2006. ${ }^{24}$ Sin embargo, la reforma electoral del 2007 dio a los partidos políticos la exclusividad de la postulación de candidaturas, la cual fue también consignada en el nuevo Código Federal de Instituciones y Procedimientos Electorales (Cofipe) del

\footnotetext{
${ }^{21}$ Ibidem, p. 652.

${ }^{22}$ Ibidem, p. 653.

${ }^{23}$ Cfr. Barceló Rojas, Daniel A., "Riesgos y oportunidades de las candidaturas independientes", Folios. Publicación de discusión y análisis, año 3, núm. 18, 2010, pp. 50-51.

${ }^{24}$ Cfr. Artículo 16, Apartado B. Constitución Política del Estado de Yucatán. Reforma publicada en el Diario Oficial del Estado el 24 de mayo de 2006; Artículo 28. Ley de Instituciones y Procedimientos Electorales del Estado de Yucatán. Publicada en el diario Oficial del Gobierno del Estado el 24 de mayo de 2006. Gracias a dicha reforma, el 20 de mayo de 2007 se celebraron elecciones en Yucatán para elegir gobernador, alcaldes y diputados locales. En el municipio de Yobaín, Yucatán, el candidato independiente José Adonaí Avilés Sierra obtuvo la alcaldía con el $40.2 \%$ de los votos emitidos.
} 
2008. ${ }^{25}$ Finalmente, el 9 de agosto de 2012 se reincorporaron; se les otorgó reconocimiento constitucional mediante la reforma del artículo 35.

En seguida se presenta una lista de casos concretos de candidaturas independientes que antecedieron y, podría decirse, cristalizaron su actual desarrollo y consolidación jurídica en nuestro país:

1. La Ley Electoral maderista de 1911, artículos 12 y 22, reconocía expresamente las candidaturas independientes.

2. La Ley Electoral de 1946, artículo 60, prohibió las candidaturas independientes. El no reconocimiento constitucional de esta figura estuvo vigente hasta el 8 de agosto de 2012.

3. En la reforma constitucional de 1977, articulo 41, los partidos políticos alcanzaron el rango constitucional. ${ }^{26}$

4. Octubre 25, 1998. María del Rosario Elizondo Salinas, candidata no registrada a la alcaldía del municipio de Santander Jiménez, Tamaulipas, ganó las elecciones con 1860 sufragios, que equivalen a 46.53\% de la votación total. ${ }^{27}$

5. Octubre 25, 2001. Manuel Guillén Monzón. El Tribunal del Poder Judicial de la Federación confirmó la resolución de las autoridades electorales de Michoacán que le negaron el registro como candidato independiente a gobernador de ese estado. ${ }^{28}$

6. Marzo 28, 2003. Gilberto Rocha (Ixtapaluca), Eugenia Alanís (Atizapán) y Arturo Nóguez (Villa Nicolás Romero). El Tribunal del Poder Judicial de la Federación confirma la resolución de las autoridades electorales del Estado de México que negaron su registro como candidatos independientes a presidentes municipales. ${ }^{29}$

7. Junio 13, 2003. Oscar Flores Rabadín y Eduardo Fernando López Castillo. El Tribunal del Poder Judicial de la Federación Desechó por

\footnotetext{
${ }^{25}$ Cfr. Artículo 218, Cofipe: "corresponde exclusivamente a los partidos políticos nacionales el derecho de solicitar el registro de candidatos a cargos de elección popular.” Nuevo Código publicado en el Diario Oficial de la Federación el 14 de enero de 2008. La modificación de la fracción IV inciso e) del artículo 116 de la Constitución establecía que los partidos políticos deben tener el "reconocido derecho exclusivo para solicitar el registro de candidatos a cargos de elección popular". La reforma constitucional fue publicada en el Diario Oficial de la Federación el 13 de noviembre de 2007.

${ }^{26}$ Cfr. Carpizo, Jorge, "La reforma política mexicana de 1977", Anuario furídico VI-1979, México, UNAM, 1980 , pp. 39 y 50.

${ }^{27}$ Cfr. Santiago Campos, Gonzalo, op. cit., p. 81.

${ }^{28}$ Cfr. González Madrid, Miguel, "Constitucionalización y regulación de las candidaturas independientes”, en Miguel González Madrid, y Alberto Escamilla Cadena (coords.), El nuevo sistema político electoral mexicano en 2015, México, UAM, 2015, p. 158.

Cfr. Garza Lozano, José Guadalupe, "Sufragio pasivo, Retos de las candidaturas independientes en Nuevo León", Décimo cuarto certamen de ensayo político, México, Comisión Estatal Electoral Nuevo León, 2014, p. 66.

${ }^{29}$ Cfr. Ibidem, p. 66.
} 
extemporáneo el recurso de inconformidad de quienes pretendían ser candidatos independientes a diputados locales en Morelos. ${ }^{30}$

8. Agosto 7, 2003. Valentín Pobedano Arce. El Tribunal del Poder Judicial de la Federación declaró improcedente y desechó su recurso de inconformidad, para postularse como candidato independiente, en contra del resultado de la elección de presidente municipal en Temixco, Morelos. ${ }^{31}$

9. Diciembre 22, 2004. José Hernández Mendoza. La Sala Superior del Tribunal Electoral del Poder Judicial de la Federación confirmó la sentencia de La Sala Electoral del Tribunal Superior de Justicia del Estado de Veracruz-Llave, que rechaza el presunto triunfo del candidato no registrado ${ }^{32}$ en el municipio de Las Vigas de Ramírez, Veracruz. ${ }^{33}$

10. Mayo 19, 2005. Mauricio Miguel Ángel Valdés Rodríguez. El Tribunal del Poder Judicial de la Federación Confirmó la negativa de las autoridades del Estado de México a recibir su registro como candidato independiente a gobernador del estado. ${ }^{34}$

11. Julio 2, 2006. Víctor González Torres, empresario farmacéutico, mejor conocido como el "Doctor Simi", participó como candidato no registrado al cargo de presidente de la república, durante las elecciones del 2 de julio de 2006. Realizó su campaña electoral como el resto de los candidatos. No obstante, "los votos por candidatos no registrados nunca fueron escrutados ni computados en esa elección". ${ }^{35}$

12. Agosto 16, 2005. Jorge Castañeda Gutman es el caso más relevante rechazado por la Suprema Corte de Justicia de la Nación y el de mayor resonancia a nivel internacional. El pleno del máximo tribunal confirmó la sentencia en su contra y negó que existiera una violación a sus derechos constitucionales al pretender obtener el registro como candidato a la presidencia de la república para las elecciones del 2006. El afectado interpuso una demanda contra el Estado Mexicano ante la Comisión Interamericana de Derechos Humanos por habérsele negado el derecho a ser votado. No obstante, el fallo de la Corte Interamericana de Derechos Humanos (CIDH) negó que el Estado mexicano haya violado el derecho a la participación política del demandante consagrado en el artículo 23 de la Convención Americana.

\footnotetext{
${ }^{30}$ Cfr. Ibidem, p. 66.

${ }^{31}$ Cfr. Ibidem, pp. 66-67.

${ }^{32}$ Los candidatos no registrados son aquellos que aparecen en las boletas electorales por adición de los mismos electores.

${ }^{33}$ Cfr. González Madrid, Miguel, op. cit., p. 158.

${ }^{34}$ Cfr. Garza Lozano, José Guadalupe, op. cit., p. 66.

${ }^{35}$ González Madrid, Miguel, op. cit., p. 159.
} 
Sin embargo, reconoció que sí violó, en perjuicio de Jorge Castañeda, "el derecho a la protección judicial" consagrado en el artículo 25 de la Convención Americana, toda vez que en México no se cuenta con un recurso efectivo para la restitución de los derechos políticos. Asimismo, la resolución de la Corte no consideró que al demandante se le hubiera violado del derecho de igualdad ante la ley. La CIDH determinó "que el Estado debe, en un plazo razonable, completar la adecuación de su derecho interno a la Convención, de tal forma que ajuste la legislación secundaria y las normas que reglamentan el juicio de protección de los derechos del ciudadano de acuerdo con lo previsto en la reforma constitucional de 13 de noviembre de 2007. Mediante dicho recurso, se garantizaría a los ciudadanos de forma efectiva el cuestionamiento de la constitucionalidad de la regulación legal del derecho a ser elegido". ${ }^{36}$

13. Mayo 20, 2007. José Adonaí Avilés Sierra ganó la presidencia municipal de Yobaín, Yucatán como candidato independiente. El otrora dos veces alcalde por el PRI en dicho municipio durante periodos alternos (1995-1998 y 2001-2004) recibió 40.2\% (552 votos) de los sufragios emitidos. $^{37}$

14. Octubre 30, 2007.J. Fernando Cristóbal Mendoza Espino. El Consejo General del Instituto Electoral de Quintana Roo le negó el registro como candidato independiente a diputado local, para el proceso electoral ordinario local 2007-2008. ${ }^{38}$

15. Mayo 2, 2009. Elisa de Anda Madrazo y Antonio Carbia Gutiérrez. El 22 de abril de 2009 presentaron al 23 Consejo Distrital del Instituto Federal Electoral en el Distrito Federal su registro como candidatos independientes (propietario y suplemente) al cargo de diputados por el principio de mayoría relativa correspondiente al 23 Distrito Electoral Federal en el Distrito Federal. Sin embargo, el Consejo les negó el registro, por ser los partidos políticos el canal exclusivo para la postulación de candidaturas. El 2 de junio de 2009, la Sala Distrito Federal del Tribunal Electoral del Poder Judicial de la Federación confirmó la resolución de la autoridad electoral. ${ }^{39}$

\footnotetext{
${ }^{36} \mathrm{CIDH}$, Caso Jorge Castañeda vs. Estados Unidos Mexicanos. Sentencia del 6 de agosto de 2008, San José de Costa Rica, Corte Interamericana de Derechos Humanos, 2008, pp. 64 y 67.

${ }^{37}$ Cfr. González Padilla, Roy, "Candidaturas independientes: ¿empoderamiento ciudadano o circulación de élites políticas por otros medios?", Revista Mexicana de Análisis Politico y Administración Pública, vol. 4, núm. 1, 2015, p. 195.

${ }^{38}$ Cfr. González Madrid, Miguel, op. cit., p. 159.

${ }^{39}$ Cfr. 23 Consejo Distrital del Instituto Federal Electoral en el Distrito Federal, Juicio para la protección de los derechos políticos electorales del ciudadano, expediente SDF-JDG-190/2009, México, Distrito Federal, 2 de junio de 2009, pp. 3-4.
} 
16. Mayo 2, 2009. Parménides Ortiz Cano. La Junta Distrital del IFE número 2 del estado de Tlaxcala le negó el registro como candidato independiente a diputado federal por el segundo distrito electoral de Tlaxcala, debido a la exclusividad de los partidos políticos para postular candidaturas, de acuerdo con lo establecido por el artículo 218 del Cofipe. La Sala Distrito Federal del Tribunal Electoral del Poder Judicial de la Federación ratificó la negativa en su sentencia emitida el 2 de junio de 2009.40

17. Marzo 15, 2012. Manuel Jesús Clouthier Carrillo solicitó al Instituto Federal Electoral el registro como candidato independiente a la presidencia de la república en el 2012, pero éste se lo negó. ${ }^{41}$ El diputado federal con licencia interpuso un juicio ante el Tribunal Electoral de Poder Judicial de la Federación, por la presunta inconstitucionalidad del artículo 218 del Código Federal Electoral de Instituciones y Procedimientos Electorales (Cofipe). Sin embargo, el 29 de marzo de 2012, la Sala Superior del Tribunal Electoral del Poder Judicial de la Federación ratificó la decisión del IFE y le negó el registro. ${ }^{42}$

18. Abril 22, 2015. León Ignacio Ruiz Ponce. La Sala Regional del Tribunal Electoral del Poder Judicial de la Federación rarificó la negativa del Consejo Distrital del Instituto Nacional Electoral en Veracruz en darle el registro como candidato independiente a la alcaldía del municipio de Xalapa, Veracruz. ${ }^{43}$

En el ámbito internacional son comunes las candidaturas independientes en la mayoría de los países. En el caso latinoamericano, la Red de Conocimientos Electorales registra pocas naciones que aún no cuentan con este tipo de candidaturas: Argentina, Brasil, Perú, Costa Rica, Guatemala, Uruguay, Surinam y Guyana. ${ }^{44}$ Sin embargo, en la región existen importantes diferencias entre las prerrogativas que la normatividad concede a los partidos políticos y a los candidatos independientes. En pocos casos sucede lo contrario, por ejemplo:

\footnotetext{
${ }^{40}$ Cfr. González Madrid, Miguel, op. cit., pp. 159-160.

${ }^{41}$ Cfr. "Clouthier solicita registro ante el IFE", Animal Político, 15 de marzo de 2012. Disponible en: http:// www.animalpolitico.com/2012/03/clouthier-solicita-registra-ante-el-ife

${ }^{42}$ Cfr. Jesús Barba, "Tribunal niega candidatura independiente a Manuel Clouthier", Noticieros Televisa, 24 de abril de 2012. [Consulta: 3 de mayo, 2016]. Disponible en http://noticierostelevisa.esmas.com/decision-2012/noticias-decision-2012/435388/declara-tribunal-improcedente-candidatura-clouthier

${ }^{43}$ González Madrid, Miguel, op. cit., p. 158.

${ }^{44}$ Cfr. Ace Project, Red de Conocimientos Electorales, Datos comparados. [Consulta: 23 de septiembre, 2016]. Disponible en: http://aceproject.org/epic-es?question=PC008\&f=a
} 
La normatividad electoral chilena coloca en igualdad de condiciones a unos y otros, lo cual refleja el interés por garantizar condiciones equitativas a ambos actores políticos. De manera semejante, el marco normativo de países como Venezuela, Colombia, Honduras, Perú, República Dominicana y algunos otros, ha apostado a la equidad de la competencia por el poder. ${ }^{45}$

De acuerdo con estudios en derecho comparado en material electoral, las candidaturas independientes no son la solución a la crisis de representación que padecen las democracias latinoamericanas. Por el contrario, podrían agravar los problemas que pretenden resolver, puesto que los partidos políticos siguen siendo los pilares de la democracia en tanto que aglutinan y articulan los intereses ciudadanos. ${ }^{46}$ Dichas candidaturas sólo podrán encontrar terreno fértil en países con democracias débiles, como las de nuestro continente, pero no en las democracias fuertes "donde los partidos políticos y las instituciones de la democracia representativa tienen siglos de existencia". ${ }^{47}$

\section{EL MARCO NORMATIVO ELECTORAL}

El marco legal que establece las bases de la participación política, y reglamenta el proceso electoral en general, especifica cuáles son las obligaciones y los derechos de las candidaturas de partido y las independientes. De entrada, es importante señalar que se trata de una legislación que favorece a los partidos políticos en perjuicio de las postulaciones independientes. Lo establecido por las reformas políticas electorales del 2012 (artículo 35), 2013 (artículo 116) y 2014 (artículo 41), impide que las candidaturas independientes compitan en igualdad de condiciones con los partidos políticos. Los candados legales colocados de manera estratégica por la Legislatura Federal y estatales vulneran el principio de equidad que por norma debería aplicarse en los procesos electorales. ${ }^{48}$ Los independientes tienen menos financiamiento que los partidos tradicionales, escaso acceso a los tiempos en radio y televisión y se les exige un alto porcentaje de firmas de los electores para el registro.

La reforma constitucional al artículo 35, publicada en el Diario Oficial de la Federación el 9 de agosto de 2012, reconoció a las candidaturas

\footnotetext{
${ }^{45}$ Espinoza Toledo, Ricardo, Valdez Raygoza, Ricardo y Carrasco Cruz, Arturo, "Los candidatos sin partido, otra forma de participación política", en Oscar Nicasio Lagunes López (coord.), Los nuevos dilemas de la democracia en México, libro en prensa, p. 82.

${ }^{46}$ Cfr. Ibidem, p. 61.

${ }^{47}$ Ibidem, p. 65.

${ }^{48}$ En el artículo 121, número 2, inciso a) de la LGIPE están reconocidos los principios constitucionales electorales de imparcialidad, certeza, legalidad, objetividad y equidad.
} 
independientes para todos los cargos de elección popular. ${ }^{49}$ Empero, el Legislativo Federal omitió modificar también el artículo 116, que daba exclusividad a las candidaturas de partido. ${ }^{50}$ Este cambio se realizaría el 27 de diciembre de 2013, fecha de publicación en el Diario Oficial de la Federación, con la inclusión de la modalidad independiente en la postulación de candidaturas. El 10 de febrero de 2014 fue adicionado el artículo 41 constitucional, para reconocer el derecho de las candidaturas sin partido a recibir tiempos en radio y en televisión que son propiedad del Estado y que administra el Instituto Nacional Electoral. ${ }^{51}$ Estos cambios normativos se realizaron para recuperar la confianza social en los partidos políticos, estimular la participación ciudadana en las candidaturas e incrementar la concurrencia en las urnas.

El proceso de registro de las candidaturas independiente se desarrolla en cuatro fases: emisión de la convocatoria por parte de las autoridades electorales; registro de aspirantes a candidatos independientes; obtención del apoyo ciudadano y la verificación del cumplimiento de requisitos.

Una vez lanzada la convocatoria, los interesados deberán hacer saber al instituto electoral correspondiente su intención de participar mediante escrito en el formato indicado. El órgano electoral les hará llegar la constancia de aspirantes. En seguida, éstos deberán presentar la documentación que acredite su personalidad moral constituida en asociación civil, que en el régimen fiscal tendrá el mismo tratamiento que un partido político de nueva creación. Además, deberán acreditar su alta "ante el Sistema de Administración Tributaria y anexar el nombre de la persona moral para recibir el financiamiento público y privado correspondiente". ${ }^{52}$ Un día después de obtener la calidad de aspirantes, podrán iniciar actividades con miras a la obtención de respaldo ciudadano. ${ }^{53}$

\footnotetext{
${ }^{49}$ Cfr. Artículo 35, fracción II. Cfr. Artículo 41, Fracción II, inciso b. Constitución Política de los Estados Unidos Mexicanos. Reforma publicada en el Diario Oficial de la Federación el 9 de agosto de 2012: "El derecho de solicitar el registro de candidatos ante la autoridad electoral corresponde a los partidos políticos así como a los ciudadanos que soliciten su registro de manera independiente y cumplan con los requisitos, condiciones y términos que determine la legislación”. Los artículos segundo y tercero transitorios preceptuaron la responsabilidad del Congreso de la Unión y de las legislaturas locales de adecuar su legislación secundaria a esta reforma en un plazo no mayor a un año, contando a partir de su entrada en vigor. Las primeras elecciones que contarían con la participación legal de la nueva figura se celebrarían el 7 de julio de 2013. En estas elecciones, Raúl de Luna Tovar ganó la alcaldía de General Enrique Estrada (Zacatecas) como candidato independiente. Consiguió el triunfo con 1377 votos: 43\% de la votación. ${ }^{50}$ Cfr. Artículo 116, fracción IV, incisos e y o. Constitución Política de los Estados Unidos Mexicanos.

${ }^{51}$ Cfr. Montoya Zamora, Raúl, Candidaturas independientes en México, México, Tribunal Electoral del Estado de Durango, Ubijus Editorial, 2015, p. 61.

${ }^{52}$ Artículo 368, párrafo 4. Ley General de Instituciones y Procedimientos Electorales. Publicada en el Diario Oficial de la Federación el 23 de mayo de 2014. El registro de una asociación civil ante notaría pública oscila entre los 6000 y 8000 pesos. Este gasto correrá por cuenta del aspirante a candidato independiente. ${ }^{53}$ Cfr. Artículo 369, párrafo 1. Para formar un nuevo partido político sólo se requiere $0.26 \%$ de la lista nominal. Sin embargo, el porcentaje que se les exige a los independientes supera varias veces esta cifra, Artículo 10, Ley General de Partidos Políticos. Decreto de reforma publicado en el Diario Oficial de la Federación el 23 de mayo de 2014.
} 
Los tiempos para obtener el porcentaje de apoyo ciudadano, así como los porcentajes requeridos para lograr la candidatura a cualquier cargo de elección popular varían en la legislación federal y en las estatales. La siguiente figura muestra la disparidad entre la legislación electoral federal y las locales en relación con estos requisitos, puesto que para el registro de candidatos independientes se exigen diferentes tiempos para reunir el porcentaje requerido de apoyo ciudadano y diferentes porcentajes de éste mismo, dependiendo del cargo de elección popular al que se aspire y la entidad federativa donde tenga lugar. El análisis evidencia la falta de homogeneidad normativa en materia electoral entre la federación y las entidades locales. Es importante resaltar que sólo se compararon las legislaciones de cuatro estados y de la federación, pues en estas demarcaciones ganaron seis candidatos independientes durante las elecciones del 7 junio de 2015.

\section{Figura 1}

Porcentaje de respaldo ciudadano para el registro de candidaturas independientes

\begin{tabular}{|c|c|c|c|}
\hline $\begin{array}{c}\text { Demarcación } \\
\text { territorial }\end{array}$ & Puesto de elección popular & $\begin{array}{c}\text { Tiempo para } \\
\text { reunir las firmas }\end{array}$ & $\begin{array}{c}\text { Porcentaje de } \\
\text { la lista nominal }\end{array}$ \\
& Presidente de la república & 120 días & $1 \%$ \\
& Diputado federal & 60 días & $2 \%$ \\
\multirow{2}{*}{ Nuevo León } & Senador & 90 días & $2 \%$ \\
& Gobernador & 30 días & $3 \%$ \\
& Diputados & 30 días & $2 \%$ \\
\hline \multirow{2}{*}{ Jalisco } & Ayuntamientos & 30 días & $3 \%-20 \%$ \\
& Gobernador & 60 días & $1 \%$ \\
& Diputados & 40 días & $2 \%$ \\
\cline { 2 - 4 } & Ayuntamientos & 40 días & $2 \%$ \\
\hline Guanajuato & Gobernador & 60 días & $3 \%$ \\
\hline \multirow{2}{*}{} & Diputados & 30 días & $3 \%$ \\
\hline Michoacán & Ayuntamientos & 45 días & $3 \%$ \\
\hline & Gobernador & 30 días & $2 \%$ \\
\hline & Diputados & 20 días & $2 \%$ \\
\hline
\end{tabular}

Fuente: Elaboración propia con base en la Ley General de Instituciones y Procedimiento Electorales, publicada en el Diario Oficial de la Federación el 23 de mayo de 2014; Llel añicipios que 0 mil, el 5\% ara muniocipcuerdo al nndienteey Electoral para el Estado de Nuevo León, publicada en el Periódico Oficial, núm. 86, el 8 de julio de 2014; Código Electoral del Estado de Michoacán de Ocampo, publicada en el Periódico Oficial el 29 de junio de 2014; Código Electoral y de Participación Ciudadana del Estado de Jalisco, Decreto núm. 24906/LX/14; Ley de Instituciones y Procedimientos Electorales para el Estado de Guanajuato, Publicada en el Periódico Oficial, núm. 102, 27 de junio de 2014. 
En este análisis, la legislatura de Guanajuato es la que más restricciones colocó a las candidaturas independientes. Los aspirantes a gobernador, diputados o alcaldes deberán reunir el porcentaje más alto del comparativo para registrar su candidatura. Además, concede periodos estrechos para que los aspirantes sin partido alcancen las firmas de respaldo ciudadano. Nuevo León coincide con Guanajuato en el porcentaje requerido al cargo de gobernador. Estos estados otorgan el tiempo más amplio para conseguir las firmas a los aspirantes a gobernador.

En Nuevo León, Jalisco, Guanajuato y Michoacán se piden los mismos porcentajes para diputados locales y alcaldes, a excepción de Nuevo León, que ha puesto los porcentajes más altos para los ayuntamientos. La Federación solicita estos mismos porcentajes para senador y diputado federal.Jalisco es el estado con el porcentaje más bajo para el cargo a gobernador, mientras que Michoacán es la entidad que menos tiempo destina a los aspirantes a diputados y alcaldes para lograr el apoyo ciudadano; junto con Nuevo León, son los estados que menos días dan para reunir las firmas a los que buscan la candidatura a gobernador.

Entre el 2014 y el 2015 se han introducido también trabas a los independientes en las legislaciones de Baja California Sur, Sinaloa, Durango, Puebla, Veracruz, Tlaxcala, Chihuahua y Tamaulipas. En Baja California se exige a los aspirantes independientes 4\% de firmas de la lista nominal para gobernador y $5 \%$ para diputados y alcaldes. En Sinaloa se les pide $5 \%$ para cualquier cargo; en Durango, Puebla, Veracruz, Chihuahua y Tamaulipas 3\% para todos los puestos de elección popular. En algunos estados, adicionalmente, se restringe la participación de candidatos que hayan sido postulados por un partido político: durante los últimos tres años para Puebla y Chihuahua y los dos últimos para Veracruz.

En Puebla se había colocado una restricción más: el tiempo para reunir las firmas era de veinte días, pero con la reforma del Código Electoral en el 2016 se extendió a treinta. ${ }^{54}$ Por lo que toca a los estados de Hidalgo y Quintana Roo, los requisitos para los candidatos independientes son, en el caso del primero, no haber participado en los procesos internos de partidos políticos en la elección de abanderados en las dos elecciones precedentes y, en el caso del segundo, haber renunciado tres años antes a su militancia partidista. En Tlaxcala los porcentajes requeridos son estridentes: 3\% para gobernador, $6 \%$ para diputados y $12 \%$ para alcaldes. ${ }^{55}$

\footnotetext{
${ }^{54}$ Cfr. Artículo 201 Ter, Apartado C, Fracción IV, Código de Instituciones y Procesos Electorales del Estado de Puebla. Reforma publicada el 9 de enero de 2016.

${ }^{55}$ A nivel internacional sólo se exige 1\% para el registro de candidaturas independientes. Cfr. Comisión Europea para la Democracia por el Derecho, Código de buenas prácticas en materia electoral. Directrices e informe explicativo, México, Tribunal Electoral del Poder judicial de la Federación, 2011, p. 15. En México es más fácil que un nuevo partido político adquiera su registro a que un candidato independiente logre su registro. Mientras a aquél se le pide $0.25 \%$ de la lista nominal para su registro, a éste se le piden porcentajes que, por lo general, superan 2\% de dicha lista. Cfr. Artículo 10, Ley General de Partidos Políticos. Decreto de reforma publicado en el Diario Oficial de la Federación el 23 de mayo de 2014.
} 
En puebla, se había puesto como obstáculo a los independientes la cláusula que exigía la presentación del elector ante el instituto electoral para corroborar las firmas de respaldo ciudadano de los candidatos independientes. El 9 de enero de 2015 fue anulada dicha restricción del Código de Instituciones y Procedimientos Electorales del Estado de Puebla. La Suprema Corte de Justicia de la Nación la invalidó como inconstitucional, aunque todavía no se ha eliminado el requisito de presentar la copia de la credencial de elector de quienes respalden la candidatura. ${ }^{56}$ De acuerdo con una nota publicada en el periódico El País, el estado de Puebla continúa siendo "uno de los estados más severos en su blindaje", pues "su legislación pide 3\% de apoyo del padrón electoral". ${ }^{57}$

Después de concluir el periodo de obtención del apoyo ciudadano, los institutos electorales verificarán si los aspirantes cumplieron con los requisitos de la LGIPE o las leyes electorales locales, según se trate de elecciones locales o federales. Los aspirantes a candidatos independientes enviarán la solicitud de registro de la candidatura independiente al secretario del consejo del instituto electoral correspondiente, para que se verifique, durante los tres días siguientes, que fueron cumplidos a cabalidad los requisitos que exige la normatividad electoral, a excepción de los porcentajes de respaldo ciudadano. El cumplimiento de uno o varios requisitos da lugar a un tiempo de 48 horas, contando a partir de la notificación al aspirante, para que sean subsanadas las deficiencias halladas.

Si éstas no se cubren o si la solicitud de registro es extemporánea, se considerarán como no presentadas. ${ }^{58}$ Ya que han sido cumplidos estos requisitos, los aspirantes deberán comprobar que reunieron el porcentaje de apoyo ciudadano requerido. Sin embargo, la LGIPE solicita la copia de la credencial de elector en la presentación de las firmas ciudadanas. ${ }^{59}$ Esta misma restricción la tienen los estados de Guanajuato ${ }^{60}$ y Jalisco, ${ }^{61}$ aunque la más dura fue introducida por la legislatura de Michoacán que, además de este requisito, demanda la comparecencia de los ciudadanos firmantes en las instalaciones del órgano electoral. ${ }^{62}$

\footnotetext{
${ }^{56}$ Cfr. Artículo 201 Ter, Fracción II, Apartado G. Código de Instituciones y Procesos Electorales del Estado de Puebla.

${ }^{57}$ Gallegos, Zoraida, "Los candados para los independientes mexicanos en 2016", El País, 19 de diciembre de 2015. [Consulta: 28 de abril, 2016]. Disponible en http://internacional.elpais.com/internacional/2015/12/19/america/1450480384_605266.html

${ }^{58}$ Cfr. Artículo 384, párrafos 1 y 2, Ley General de Instituciones y Procedimiento Electorales. Publicada en el Diario Oficial de la Federación el 23 de mayo de 2014.

${ }^{59}$ Cfr. Artículo 385, párrafo 2, inciso b.

${ }^{60}$ Cfr. Artículo 311, Fracción III, inciso i, Ley de Instituciones y Procedimientos Electorales para el Estado de Guanajuato, Publicada en el Periódico Oficial, núm. 102, 27 de junio de 2014.

${ }^{61}$ Cfr. Artículo 710, párrafo 2, inciso b, Código Electoral y de Participación Ciudadana del Estado de Jalisco. Decreto de reforma núm. 24906/LX/14.

${ }^{62}$ Cfr. Artículo 312, Código Electoral del Estado de Michoacán de Ocampo. Publicado en el Periódico Oficial del Estado de Michoacán, el 29 de junio de 2014, tomo 159, núm. 77, segunda sección.
} 
Otra restricción, no menos importante, explícita tanto en la legislación nacional como en la local en materia electoral, consiste en la imposibilidad de los candidatos independientes para competir por los cargos de elección popular por el principio de representación proporcional. La legislación sólo les permite postularse por el principio de mayoría relativa a los cargos de presidente de la república, senador de la república, diputado federal y diputado local, gobernador e integrantes de los ayuntamientos. ${ }^{63}$ Los partidos políticos siguen teniendo el monopolio en la postulación de candidaturas bajo este principio. ${ }^{64}$ Este es otro elemento que pone en desventaja a los candidatos independientes frente a los partidos políticos y que infringe el principio de equidad que debe regir la contienda electoral. ${ }^{65}$

\section{EL FINANCIAMIENTO PÚBLICO Y PRIVADO}

Tanto las candidaturas de partido como las independientes reciben financiamiento público y privado, sólo que en aquéllas se privilegia el primer tipo de financiamiento; en éstas, el segundo. Las candidaturas de partido reciben financiamiento público desde la precampaña, pero las nuevas candidaturas no tienen derecho a recibir recursos públicos; es financiado con recursos privados. No deberá rebasar 10\% del tope fijado para las campañas. Las candidaturas independientes recibirán financiamiento público únicamente para cubrir los gastos de las campañas electorales. La LGIPE premia a los partidos de mayorías otorgándoles más recursos financieros y más tiempo en radio y televisión que a los partidos que tienen una menor recepción de votos. Algunos partidos

\footnotetext{
${ }^{63}$ Cfr. Artículo 362, Ley General de Instituciones y Procedimientos Electorales; Artículo 191, Ley Electoral para el Estado de Nuevo León; Artículo 4, Código Electoral del Estado de Michoacán de Ocampo; Artículo 687, Código Electoral y Participación Ciudadana del Estado de Jalisco; Artículo 7, Ley de Instituciones y Procedimientos Electorales para el Estado de Guanajuato. Los candidatos postulados por el principio de representación proporcional también se les conoce como candidatos de lista, previamente seleccionados por los partidos políticos. La asignación de escaños bajo este principio se realiza a partir del porcentaje de votos obtenido por los partidos políticos en cada elección. Los partidos que obtienen la mayor cantidad de votos en una lección tienen derecho a más escaños en los congresos locales y en el federal. En México sólo una parte de los diputados y senadores del Congreso de la Unión y de los diputados de los congresos locales son elegibles mediante el principio de representación proporcional.

${ }^{64}$ Cfr. Constitución Política de los Estados Unidos Mexicanos, artículo 54, fracciones I-III. Sólo a nivel municipal, en algunos estados de la república, se permiten la participación de candidatos independientes por el principio de representación para la asignación de regidores en los ayuntamientos, siempre y cuando estos candidatos alcancen 3\% de la votación total emitida. Este es el caso de Colima, Guanajuato, Guerrero, Jalisco, San Luis Potosí y Yucatán. Cfr. Rivera Hernández, Claudia, "Percepción de la ciudadanía sobre las candidaturas independientes en el proceso electoral 2015”, en Oscar Nicasio Lagunes López (coord.), Los nuevos dilemas de la democracia en México, libro en prensa, pp. 131-133.

${ }^{65}$ Cfr. La LGIPE, artículo 121, número 2, inciso a) reconoce los principios constitucionales electorales de imparcialidad, certeza, legalidad, objetividad y equidad en la contienda electoral. No pocas veces esta ley subraya que el principio de equidad debe regir la contienda electoral. La Constitución, en su artículo 134, párrafo 6, consagra el principio en términos de "equidad en la competencia entre partidos políticos", aunque nunca hace alusión a la equidad que debe haber entre candidaturas independientes y partidos políticos.
} 
pequeños, los de reciente creación y las candidaturas independientes siempre serán considerados como partidos de reciente creación.

El criterio para el financiamientos de los partidos políticos en el ámbito federal y local, para cubrir los gastos de sus actividades ordinarias es el siguiente: $30 \%$ se reparte de manera equitativa entre los partidos políticos y el resto se distribuye de acuerdo con el porcentaje votos obtenidos por los partidos políticos en la elección inmediata anterior ${ }^{66}$ En el año en que se celebren elecciones para renovar el poder ejecutivo de la federación y el de los estados, así como las cámaras del congreso de la unión y de los estados, los partidos políticos recibirán para gastos de campaña un monto equivalente a $50 \%$ del presupuesto que reciben anualmente para actividades ordinarias permanentes. ${ }^{67}$ En el caso que sólo se elijan diputados federales y locales, obtendrán $30 \%$ del presupuesto anual para sufragar los gastos de las campañas electorales. ${ }^{68}$

El presupuesto de egresos de la Federación del 2015 fue de $\$ 4,694,677,400,000$. Los partidos políticos recibieron una bolsa de $\$ 5,355,522,828$, lo que equivale a $0.11 \%$ del presupuesto de la Federación. ${ }^{69}$ Estos datos colocan a México como el país que más dinero destina a los partidos políticos, si se le compara con los países latinoamericanos y europeos. Sólo para costear las elecciones ordinarias del 2015, el Congreso destinó a estas instituciones una bolsa próxima a los 37 millones de dólares. ${ }^{70}$ Mientras los candidatos sin partido recibieron $\$ 23,457,244$ para gastos de campaña, los partidos tradicionales se embolsaron \$306,726,482.66 (PRI), $\$ 257,623,465.59$ (PAN) y \$ 196,394,734.86 (PRD), sin contar el presupuesto que obtienen cada año dé la federación para actividades ordinarias, que es el mayor financiamiento que reciben. ${ }^{71}$

\footnotetext{
${ }^{66}$ Cfr. Artículo 41, Base II, inciso a). Constitución Política de los Estados Unidos Mexicanos. Reforma publicada el 27 de enero de 2016.

${ }^{67}$ Cfr. Artículo 51, párrafo 1, inciso b, fracción I. Ley General de Partidos Políticos. Publicada en el Diario Oficial de la Federación el 23 de mayo de 2014.

${ }^{68}$ Cfr. Artículo 51, párrafo 1, inciso b, fracción II.

${ }^{69}$ Cfr. Capítulo 2, artículo 2. Presupuesto de Egresos de la Federación para el Ejercicio Fiscal 2015. [Consulta: 16 de junio, 2016]. Disponible en: http://www.diputados.gob.mx/PEF2015/exposicion/decreto_ presupuesto.pdf

Acuerdo del Consejo General del Instituto Nacional Electoral, INE/CG341/2014, p. 24. [Consulta: 16 de junio, 2016]. Disponible en: http://www.ine.mx/archivos3/portal/historico/recursos/IFE-v2/DEA/DEAPresupuestoInformes/DEA-PresupuestoIFE/PresupuestoIFE-docs/2015/INE-CG341-2014_PPT-2015.pdf ${ }^{70}$ Cfr. Díaz Santana, Héctor, "11 México", en Financiamiento Político y Regulación de Campañas Electorales en Amerita Latina, The Carter Center, Atlanta, 2015, pp. 22-23.

${ }^{71}$ Cfr. Instituto Nacional Electoral, Numeralia proceso electoral 2014-2015, México, Instituto Nacional Electoral, 2015, p. 20. [Consulta: 20 de mayo, 2016]. Disponible en: http://www.ine.mx/2015/Docs/Numeralia_ProcesoElectoral_2014-2015.pdf

El cálculo de los montos presupuestales de los partidos políticos y los candidatos independientes en el 2015, de acuerdo con los porcentajes anteriormente señalados, se encuentran en el Acuerdo del Instituto Nacional Electoral, INE/CG01/2015. [Consulta: 14 de mayo, 2016]. Disponible en: http://www.ine.mx/archivos3/portal/historico/recursos/IFE-v2/DS/DS-CG/DS-SesionesGG/CG-acuerdos/2015/01_Enero/CGext201501-14/CGex201501-14_ap_1.pdf
} 
Para diputados federales por el principio de mayoría relativa, el límite máximo de gastos autorizado fue de 1260038 pesos. $^{72}$ En las entidades donde los independientes ganaron las elecciones, el límite máximo de gastos permitidos fueron los siguientes: para gobernador de Nuevo León, \$8,882,613.91, presidente de García, \$1,013,271.82, ${ }^{73}$ presidente de Comonfort, Guanajuato, $\$ 470,409.81^{74}$ y presidente de Morelia, Michoacán, \$3,314,397.93. ${ }^{75}$ En la elección de diputados locales de mayoría relativa en Jalisco, el tope fue de $\$ 1,235,538.13$ pesos. $^{76}$ Los candidatos independientes sólo podían utilizar $10 \%$ de estos topes.

\section{LOS ESPACIOS EN RADIO Y TELEVISIÓN}

En la distribución de los tiempos de radio y televisión sucede algo similar a la repartición del presupuesto público entre los partidos políticos. Para el otorgamiento de los tiempos en radio y televisión que son propiedad del Estado, la LGIPE considera a las candidaturas independientes como un partido de nuevo registro, por lo que podrán anunciarse en estos medios sólo en el periodo de las campañas electorales. ${ }^{77}$ Por esta razón se les otorga menos minutos que a los partidos políticos. No tienen derecho a anunciarse en estos medios en el periodo de obtención de apoyo ciudadano, mientras que los precandidatos de los partidos pueden hacerlo durante las precampañas políticas. ${ }^{78}$ Las prerrogativas de los partidos políticos en relación con los tiempos en radio y televisión son evidentes, pero atentan contra la promoción equitativa que deberían tener todas las candidaturas. ${ }^{79}$

El criterio a nivel federal para distribuir los tiempos en radio y televisión entre los partidos y políticos y las candidaturas independientes es inequitativo. La ley ha fijado que 30\% del tiempo destinado a la publicidad electoral en estos medios se reparta por igual entre todos los candidatos, sean de partido

\footnotetext{
${ }^{72}$ Cfr. INE, Numeralia..., op. cit., p. 21.

${ }^{73}$ Cfr. Consejo Estatal Electoral de Nuevo León (CEE), Acuerdo del Consejo General Estatal Electoral de Nuevo León, CEE/CG/07/2014. Considerando décimo primero. [Consulta: 22 de abril, 2016]. Disponible en: http://www.cee-nl.org.mx/transparencia/documentos/art/20150317-precampanas.pdf

${ }^{74}$ Cfr. Instituto Electoral del Estado de Guanajuato (IEEG), Boletín informativo, núm. 038 del 19 de marzo de 2015.

${ }^{75}$ Cfr. Instituto Electoral de Michoacán (IEM), Acuerdo del Consejo General, CG-20/2014. [Consulta: 22 de abril, 2016]. Disponible en: http://transparencia.congresomich.gob.mx/media/documentos/periodicos/cua-7514_1.pdf

${ }^{76}$ Cfr. Instituto Electoral y de Participación Ciudadana de Jalisco (IEPCJ), Acuerdo del Consejo General, IEPC-ACG-066/2014. [Consulta: 22 de abril, 2016]. Disponible en: http://www.iepcjalisco.org.mx/sites/default/files/tope_de_gastos_2014-2015.pdf

${ }^{77}$ Cfr. Artículo 369, párrafo 1. Ley General de Instituciones y Procedimiento Electorales. Publicada en el Diario Oficial de la Federación el 23 de mayo de 2014. Los candidatos independientes podrán usar medios distintos a la radio y a la televisión en la etapa de obtención del respaldo ciudadano, siempre y cuando no sean actos anticipados de campaña. Se trata de medios impresos y redes sociales, entre otros.

${ }^{78}$ Cfr. Artículo 226, párrafo 4.

${ }^{79}$ Cfr. Artículo 159, párrafo 2; Artículo 182, inciso d.
} 
o independientes. El resto se repartirá atendiendo al criterio de partidos de mayoría ${ }^{80}$ Es decir, los partidos que recibieron más votos en la elección inmediata anterior tendrán más minutos en anuncios publicitarios que el resto de los partidos con menos votos, incluyendo los candidatos independientes, los cuales seguirán siendo considerados como un "partido de nuevo registro" en la fórmula de repartición de presupuesto y minutos en dichos medios. ${ }^{81}$

Los resultados del proceso electoral 2014-2015 muestran que las candidaturas de partido recibieron tiempo en radio y televisión desde las precampañas electorales. ${ }^{82}$ En cambio, las candidaturas independientes sólo accedieron a estos medios a partir de las campañas electorales, y se les otorgó el tiempo que corresponde a un partido político de nuevo registro. Esta diferenciación en la distribución de los tiempos para ambos tipos de candidaturas provocó que los independientes compitieran en desventaja desde el inicio de la contienda electoral.

Los veintidós candidatos sin partido que participaron en las elecciones de diputados federales por el principio de mayoría relativa sólo consiguieron 155936 anuncios publicitarios, en tanto que los partidos políticos alcanzaron a beneficiarse con un total de 27408688 anuncios en dichos medios; 2986549 anuncios publicitarios fueron para el Partido Revolucionario Institucional (PRI). La desventaja de los independientes se debe a la restricción normativa que prohíbe su acceso a los tiempos de radio y televisión en igualdad de condiciones con los partidos políticos. ${ }^{83}$

\section{LOS CANDIDATOS INDEPENDIENTES EN EL PROCESO ELECTORAL 2014-2015}

Durante el proceso electoral concurrente 2014-2015 obtuvieron su registro 133 aspirantes a candidatos independientes, de los cuales 79 compitieron por una presidencia municipal o jefatura delegacional (59.4\%), 29 participaron por una diputación local $(21 \%), 22$ para por una diputación federal $(16.5 \%)$ y 3 para gobernador $(2.2 \%)$. Los estados con el mayor número de registro de aspirantes para cualquier cargo de elección popular fueron Nuevo León, con veintitrés solicitudes; Michoacán, con doce; el Distrito Federal y el Estado de

\footnotetext{
${ }^{80}$ Cfr. Artículo 167, párrafos 1 y 4, Ley General de Instituciones y Procedimiento Electorales. Publicada en el Diario Oficial de la Federación el 23 de mayo de 2014.

${ }^{81}$ La LGIPE no especifica si serán tomados en cuenta los votos obtenidos por los candidatos independientes en la elección inmediata anterior para el cálculo del presupuesto que se les destinará, porque estos candidatos en su conjunto no constituyen un partido político.

${ }^{82}$ Inicio de las campañas electoras: Guerrero, Nuevo León, Sonora y San Luis Potosí, 6 de marzo; Colima, 7 de marzo; Campeche, 14 de marzo; Baja California Sur, Guanajuato, Jalisco, Michoacán, Querétaro y Yucatán, 5 de abril; Distrito Federal, Morelos y Tabasco, 20 de abril; Estado de México, 1 de mayo. ${ }^{83}$ Cffr. INE, Numeralia..., op. cit., p. 23. Los anuncios publicitarios de las precampañas, intercampañas y campañas a nivel federal y local, abarcan del 8 de octubre de 2014 al 4 de junio de 2015 .
} 
México, con once peticiones de registro cada uno ante los institutos electorales correspondientes (figura 2). ${ }^{84}$

Los veintidós candidatos independientes registrados para la elección a diputados federales, en 2015, se convirtieron en la tercera fuerza electoral en los veinte distritos donde compitieron. En estos distritos, los votos que recibieron los independientes sumaron 225500 , equivalentes a $10.2 \%$ de la votación (2 217 140); superaron al PRD y Morena. Sin embargo, en las elecciones locales y federales, las candidaturas independientes apenas alcanzaron 0.57\% de la votación total (39 872757 votos), muy por debajo de Morena (8.39\%), Partido Humanista $(2.14 \%$ ) y Encuentro Social $(3.32 \%)$, partidos creados en julio de $2014 .{ }^{85}$ De los 133 candidatos independientes registradas en el ámbito federal y local durante el proceso electoral 2014-2015, sólo seis ganaron las elecciones del 7 de junio de 2015.

Figura 2

Número de candidatos independientes por entidad federativa

\begin{tabular}{|c|l|c|c|c|c|c|c|}
\hline No. & \multicolumn{1}{|c|}{ Entidad } & $\begin{array}{c}\text { Diputado } \\
\text { federal }\end{array}$ & $\begin{array}{c}\text { Diputado } \\
\text { local }\end{array}$ & $\begin{array}{c}\text { Gober- } \\
\text { nador }\end{array}$ & $\begin{array}{c}\text { Presidente } \\
\text { municipal }\end{array}$ & Total & $\%$ \\
\hline 1 & Nuevo León & 1 & 11 & 1 & 10 & 23 & 17.29 \\
\hline 2 & Michoacán & & 1 & & 11 & 12 & 9.02 \\
\hline 3 & Distrito Federal & 1 & 3 & & 7 & 11 & 8.27 \\
\hline 4 & Estado de México & & 2 & & 9 & 11 & 8.27 \\
\hline 5 & Baja California Sur & & 6 & 1 & 1 & 8 & 6.02 \\
\hline 6 & Querétaro & & & & 7 & 7 & 5.26 \\
\hline 7 & Sonora & & 2 & & 4 & 6 & 4.51 \\
\hline 8 & Jalisco & & 1 & & 4 & 5 & 3.76 \\
\hline 9 & Sinaloa & & & & 5 & 3.76 \\
\hline 10 & Veracruz & & & & 4 & 3.01 \\
\hline 11 & Guerrero & & & & 3 & 3 & 2.26 \\
\hline 12 & Morelos & & & & 3 & 3 & 2.26 \\
\hline 13 & San Luis Potosí & & & & 2 & 2 & 1.50 \\
\hline
\end{tabular}

\footnotetext{
${ }^{84}$ Cfr. Tribunal Electoral del Poder Judicial de la Federación (TEPJF), "Las candidaturas independientes en el proceso electoral 2014-2015". [Consulta: 2 de mayo, 2016]. Disponible en: http://portales. te.gob.mx/candidaturas-independientes/content/las-candidaturas-independientes-en-el-proceso-electoral-2014-2015

La creación de los tres partidos políticos señalados fue aprobada por el INE el 9 de julio de 2014.

${ }^{85}$ La comparación se tomó de Alanís Figueroa, María del Carmen, "Los grandes dilemas de las candidaturas independientes", Tercer Seminario "Homenaje a don Jesús Reyes Heroles: Las reformas electorales como fortalecimiento a nuestro sistema democrático", México, INE, TEPJF, UNAM, 2015, pp. 16 y 18. Los datos que la autora presenta en su ponencia fueron actualizados, con base en INE, votos por partido a nivel nacional y votos por partido por distrito. [Consulta: 3 de mayo, 2016]. Disponibles en: http://computos2015.ine.mx/Nacional/VotosPorPartido/
} 


\begin{tabular}{|c|l|c|c|c|c|c|c|}
\hline 14 & Tamaulipas & 3 & & & & 3 & 2.26 \\
\hline 15 & Guanajuato & & & & 2 & 2 & 1.50 \\
\hline 16 & Puebla & 2 & & & & 2 & 1.50 \\
\hline 17 & Yucatán & & & & 2 & 2 & 1.50 \\
\hline 18 & Campeche & & 1 & 1 & & 2 & 1.50 \\
\hline 19 & Chihuahua & 1 & & & & 1 & 0.75 \\
\hline 20 & Hidalgo & 1 & & & & 1 & 0.75 \\
\hline 21 & Nayarit & 1 & & & & 1 & 0.75 \\
\hline 22 & Quintana Roo & 1 & & & & 1 & 0.75 \\
\hline 23 & Tabasco & 1 & 1 & & 6 & 8 & 6.02 \\
\hline 24 & Tlaxcala & 1 & & & & 1 & 0.75 \\
\hline 25 & Chiapas & & 1 & & 8 & 9 & 6.77 \\
\hline & Total & 22 & 29 & 3 & 79 & 133 & \\
\hline
\end{tabular}

Fuente: Arellano Trejo, Efrén, Origen y balance de las candidaturas independientes, Documento de trabajo núm. 193, junio de 2015, México, Centro de Estudios Sociales y de Opinión Pública, 2015, pp. 16-17. Cuadro actualizado y corregido a partir del TEPJF, Las candidaturas independientes en el proceso electoral 2014-2015. [Consulta: 13 de junio, 2016]. Disponible en http://portales.te.gob.mx/candidaturas-independientes/content/ las-candidaturas-independientes-en-el-proceso-electoral-2014-2015

\section{LOS SEIS TRIUNFOS INDEPENDIENTES}

A nivel federal, sólo un candidato independiente a diputado federal, de los veintidós registrados, ganó la elección con 42.45\% de votos: Manuel Jesús Clouthier Carrillo, por el distrito 5 de Culiacán, Sinaloa. ${ }^{86}$ A nivel local, Jaime Heliodoro Rodríguez Calderón "El Bronco" se convirtió en el primer gobernador independiente de Nuevo León. Consiguió 48.82\% de los votos emitidos, lo que representa 1020552 sufragios a su favor. En las elecciones municipales vencieron tres independientes: César Adrián Valdés Martínez en García, Nuevo León, con $41.70 \%$ de los votos emitidos, Alfonso Jesús Martínez Alcázar en Morelia, Michoacán, con 27.70\% de los votos y José Alberto Méndez Pérez en Comonfort, Guanajuato, con 30.03\% de los votos. En Jalisco, José Pedro Kumamoto Aguilar se llevó las elecciones a diputado local por el distrito 10, con sede en Zapopan; obtuvo $37.52 \%$ de los votos. ${ }^{87}$

En la siguiente figura se aprecian los porcentajes de la lista nominal de apoyo ciudadano reunidos por los seis candidatos independientes para el registro de sus candidaturas, así como el porcentaje de votación durante la jornada electoral del 7 de junio de 2015. Se presenta, además, un comparativo

\footnotetext{
${ }^{86}$ Cfr. INE, Elección de Diputados Federales 2015. Disponible en: http://computos2015.ine.mx/Entidad/ VotosPorPartido/detalle.html\#!/25

${ }^{87}$ Cfr. CEE, Resultados Electorales 2015. Disponible en: http://ceeresultadosweb.azurewebsites.net/ cg_3_E_1.html
} 
de los porcentajes de participación ciudadana entre estas elecciones y las del proceso electoral inmediato anterior, correspondientes al 2009 y 2012. Entre los datos resaltan los porcentajes de respaldo ciudadano que alcanzaron los candidatos independientes para su registro. Ello a pesar de que la normatividad electoral de las entidades federativas en las que participaron exigían porcentajes muy elevados. En algunos casos, el porcentaje de firmas que obtuvieron los independientes triplicaron o quintuplicaron el requerido por los órganos electorales.

\section{Figura 3}

Candidatos independientes que ganaron las elecciones en el 2015

\begin{tabular}{|c|c|c|c|c|c|c|c|}
\hline Nombre & Cargo & \begin{tabular}{|l|} 
Votación \\
obtenida
\end{tabular} & $\%$ & $\begin{array}{c}\text { Firmas } \\
\text { exigidas }\end{array}$ & $\begin{array}{l}\text { Firmas } \\
\text { reunidas }\end{array}$ & \begin{tabular}{c|} 
Participacion \\
ciudadana 2015
\end{tabular} & \begin{tabular}{|c|} 
Elección anterior \\
$2009 / 2012$
\end{tabular} \\
\hline $\begin{array}{l}\text { Jaime Heliódoro } \\
\text { Rodríguez } \\
\text { Calderón }\end{array}$ & $\begin{array}{l}\text { Gobernador de Nuevo } \\
\text { León }\end{array}$ & $1,020,552$ & $48.82 \%$ & $103,294(3 \%)$ & $334,480(9.7 \%)$ & $58.7 \%$ & $54.6 \%$ \\
\hline $\begin{array}{l}\text { César Adrián } \\
\text { Valdés Martínez }\end{array}$ & \begin{tabular}{|l|} 
Presidente Municipal \\
de García, Nuevo \\
León
\end{tabular} & 25,557 & $41.70 \%$ & $5,500(3 \%)$ & $28,000(15.3 \%)$ & $55.5 \%$ & $57.4 \%$ \\
\hline $\begin{array}{l}\text { José Alberto } \\
\text { Méndez Pérez }\end{array}$ & \begin{tabular}{|l|} 
Presidente Municipal \\
de Comonfort, \\
Guanajuato \\
\end{tabular} & 7,873 & $28.94 \%$ & $1,650(3 \%)$ & $3,500(6.4 \%)$ & $47.83 \%$ & $58.04 \%$ \\
\hline $\begin{array}{l}\text { Alfonso Jesús } \\
\text { Martínez Alcázar }\end{array}$ & $\begin{array}{l}\text { Presidente Municipal } \\
\text { de Morelia, } \\
\text { Michoacán }\end{array}$ & 75,380 & $27.70 \%$ & $11,500(2 \%)$ & $3,204(2.3 \%)$ & $48.50 \%$ & $54.78 \%$ \\
\hline $\begin{array}{l}\text { Manuel Jesús } \\
\text { Clouthier Carillo }\end{array}$ & \begin{tabular}{|l|} 
Diputado Federal, \\
Distro 5, Culiacán, \\
Sinaloa
\end{tabular} & 43,730 & $42.45 \%$ & $5,770(2 \%)$ & $11,960(6.7 \%)$ & $35.01 \%$ & $60.94 \%$ \\
\hline $\begin{array}{l}\text { José Pedro } \\
\text { Kumamoto } \\
\text { Aguilar }\end{array}$ & \begin{tabular}{|l|} 
Diputado Local, \\
Distrito 10, Zapopan, \\
Jalisco
\end{tabular} & 57,215 & $37.53 \%$ & $5,500(2 \%)$ & $7,200(2.6 \%)$ & $51.94 \%$ & $69.75 \%$ \\
\hline
\end{tabular}

Fuente: Elaboración propia con base en Lagunes López, Oscar Nicasio y Arellanes Jiménez, Paulino Ernesto, "Entre la partidocracia y la independencia. Las candidaturas independientes en las elecciones de 2015”, en Oscar Nicasio Lagunes López (coord.), Los nuevos dilemas de la democracia en México, Libro en prensa, pp. 193-204.

En el dictamen de Senado de la República sobre el proyecto de reforma política para el reconocimiento constitucional de las candidaturas independientes, se dice que "la participación ciudadana está en el centro de la reforma". ${ }^{88}$ Empero, los datos duros permiten inferir que, salvo el caso de

\footnotetext{
${ }^{88}$ Arellano Trejo, Efrén, Origen y balance de las candidaturas independientes, Documento de trabajo núm. 193, junio de 2015, México, Centro de Estudios Sociales y de Opinión Pública, 2015, p. 6.
} 
Jaime Heliodoro en Nuevo León, las candidaturas independientes no incrementaron los porcentajes de participación en relación con la elección inmediata anterior, pues fueron muy inferiores a éstas, como se constata en la figura precedente. En el caso de las elecciones para gobernador en Nuevo León en el 2015, la participación ciudadana alcanzó $58.7 \%$, a diferencia de $54.6 \%$ obtenido en la elección inmediata anterior del $2009 .{ }^{89}$ Esto significa $4.1 \%$ más de participación ciudadana en aquéllas. En la elección de Comonfort, que dio el triunfo a José A. Méndez, la participación ciudadana llegó al 47.83\%, $10.21 \%$ menos que en el $2012(58.04 \%) \cdot{ }^{90}$ En la elección de Morelia, cuyo ganador fue Alfonso Martínez, la participación fue de $48.50 \%$, 6.28\% menos que en el $2012(54.78 \%) .^{91}$

En la elección de García, Nuevo León, que dio la victoria a César A. Valdés, el porcentaje de participación ciudadana alcanzó 55.5\%, 1.9\% inferior a la del $2012(57.4 \%) .{ }^{92}$ En la elección de diputado federal en el distrito 5 de Culiacán Sinaloa, donde Manuel Clouthier avasalló a sus contrincantes, el porcentaje de participación ciudadana fue de 35.01\%, 25.93\% menos que en el $2012(60.94 \%) .{ }^{93}$ Por lo que respecta a la elección a diputado local por el distrito 10 de Zapopan, Jalisco, Kumamoto se convirtió en el primer independiente en ganar la elección. La participación ciudadana en este distrito en la elección del 2015 fue de $51.94 \%$, contra $69.75 \%$ del 2012 , $18.01 \%$ menos que en éstas últimas. ${ }^{94}$ En las elecciones federales 2015 la participación ciudadana tampoco aumentó, sino que decreció 15.61 puntos porcentuales en relación con la elección anterior, si se toma en cuenta que en el 2015 ésta fue de $47.72 \%$ y en el 2012 de $63.33 \%$. Estos datos demuestran

\footnotetext{
${ }^{89}$ Cfr. CEE, Memorias y estadísticas. Informe del proceso electoral Nuevo León 2011-2012, Monterrey, CEe, 2013, p. 173. [Consulta: 22 de septiembre, 2016]. Disponible en: https://www.ceenl.mx/memorias/2012/MemoriasyEstadisticas_2012_low.pdf

La lista nominal es el número total de electores que disponen de credencial para votar vigente y que están registrados en el padrón electoral.

${ }^{90}$ Cfr. IEEG, Memoria del proceso electoral 2012, Guanajuato, IEEg, 2012, p. 22; también Cfr. Lista Nominal del Ayuntamiento de Comonfort 2015. [Consulta: 26 de febrero, 2016]. Disponible en: http://www.ieeg.org. $\mathrm{mx} / \mathrm{prep} /$ UbicacionGral.php

${ }^{91}$ Cfr. IEM, Memoria. Proceso electoral ordinario 2011, tomo 1, Morelia, IEM, p. 592; también Cfr. Cómputos municipales 2015. [Consulta: 27 de febrero, 2016]. Disponible en: http://www.iem.org.mx/index.php/ archivo-documental/file/8711-computo-ayuntamientos-2015

${ }^{92}$ Cfr. CEe, Resultados de las Elecciones de Ayuntamiento 2015. [Consulta: 25 de febrero, 2016]. Disponible en: http://ceeresultadosweb.azurewebsites.net/eleccionc_1_M.html

${ }_{93}$ Cfr. INE, Atlas de Resultados Electorales Federales 1991-2012. Sistema de Consulta de la Estadística de las Elecciones Federales 2011-2012. [Consulta: 19 de abril, 2016]. Disponible en: http://siceef.ife.org. $\mathrm{mx} /$ pef2012/SICEEF2012.html\#

INE, Programa de Resultados Electorales Preliminares 2015. [Consulta: 23 de febrero, 2016]. Disponible en: http://prep2015.ine.mx/Entidad/VotosPorPartido/detalle.html\#!/25

${ }^{94}$ Cfr. Instituto Electoral y de Participación Ciudadana de Jalisco, Memoria del proceso electoral local ordinario 2014-2015, Guadalajara, IEPCJ, 2015, p. 158; Cfr. Instituto Electoral y de Participación Ciudadana de Jalisco, Memoria del proceso electoral local ordinario 2011-2012, Guadalajara, IEPCJ, 2013, pp. 99 y 173.
} 
que las candidaturas independientes no incidieron positivamente en la participación ciudadana. ${ }^{95}$

La mayoría de los candidatos independientes que triunfaron en las elecciones de 2015 militaron en partidos políticos. Algunos de ellos tienen sus propias empresas. A excepción de Kumamoto y César A. Valdés, los independientes tienen una larga historia de militancia partidista:Jaime Rodríguez y José Méndez formaron parte del Partido Revolucionario Institucional (PRI), mientras que Alfonso Martínez y Manuel Clouthier habían pertenecido al Partido Acción Nacional (PAN). Todos ellos ganaron cargos públicos siendo miembros de sus respectivos partidos y ahora lo logran nuevamente como independientes. El éxito de los seis candidatos independientes se debió a varios factores coyunturales. Por un lado, gracias al reconocimiento jurídico de las candidaturas independientes, al hartazgo ciudadano ante los partidos políticos y al uso de las redes sociales; por el otro, al expertise de los candidatos independientes y a la aplicación de una política horizontal. ${ }^{96}$

\section{CONCLUSIONES}

Las leyes en materia electoral benefician en demasía a los partidos políticos tradicionales de mayor recepción de votos en perjuicio de los candidatos independientes y de los partidos de reciente creación. Esto atenta contra el principio de equidad que debe regir toda contienda electoral. En este sentido, es prioritario reformar la legislación vigente para hacer prevalecer este principio: mismos tiempos para todos los candidatos y mismo presupuesto para financiar las candidaturas a puestos de elección popular. En segundo lugar, debe reducirse el presupuesto que se destina a los partidos políticos. Existen dos razones más para hacerlo, por un lado, México es el país que más dinero eroga a los partidos políticos a nivel mundial, sin que por ello

\footnotetext{
${ }^{95}$ Cfr. INE, "Las elecciones del primero de julio: cifras, datos y resultados". [Consulta: 22 de abril, 2016]. Disponible en: http://www.ine.mx/archivos3/portal/historico/recursos/IFE-v2/CNCS/CNCS-IFEResponde/2012/Julio/Le010712/Le010712.pdf

El proceso electoral del 2012 ha sido el más grande en la historia de México. Si se compara el porcentaje de participación ciudadana en las elecciones donde contendieron los independientes con la media de participación en cada estado en la que tuvieron presencia (Guanajuato: 45.73\%; Michoacán: 54.40\%), y la nacional $(47.7 \%)$ en el caso de la elección a diputados federales, puede hallarse que la participación ciudadana no fue mayor, salvo en Jalisco $(51.36 \%$ ) y Nuevo León (59.65\%). Cfr. Rivera Hernández, Claudia, op. cit., pp. 136-138.

${ }^{96}$ Como miembro del PRI, Jaime Rodríguez "El Bronco", fue diputado federal en 1992 y diputado local en 1997. En el 2000 contendió por la presidencia de Guadalupe, Nuevo León, sin tener éxito. En el 2009 ganó la alcaldía de García, Nuevo León (2009-2012); César Adrián Valdez Martínez fue su secretario en la alcaldía; José Alberto Méndez Pérez fue alcalde de Comonfort, Guanajuato (2000-2003) con el respaldo del pan. Militante también de este partido, Alfonso Jesús Martínez Alcázar fue diputado federal suplente en la LIX Legislatura (2003-2006) y diputado propietario local en la LXX Legislatura (2005-2008) del Congreso de Michoacán; Manuel Jesús Clouthier Carrillo perteneció al blanquiazul hasta el año 2012; ha sido diputado federal en la LXI Legislatura (2009-2012) por el PAN, pero sin militar en el partido.
} 
mejore la calidad de la democracia o se fortalezca la confianza social en estas instituciones; por el otro, los presupuestos elevados que reciben los partidos hacen que estos sean proclives a la corrupción y al derroche.

Los aspirantes a candidatos independientes sólo deberían reunir 1\% de firmas ciudadanas de respaldo ciudadano para el registro de su candidatura a cualquier puesto de elección popular, como se hace a nivel internacional. Cualquier otro porcentaje es desproporcionado e impide la participación ciudadana mediante esta figura. Por otro lado, la exigencia de la autoridad electoral a los independientes de anexar la copia de la credencial de elector en la documentación que será sometida a verificación es redundante, puesto que es suficiente con proporcionar el dato de la clave de elector. Este requisito debe eliminarse de la LGIPE y de la normatividad local en materia electoral, pues sólo obstruye el proceso de registro de los aspirantes a candidatos independientes.

Aunque los partidos políticos ya no tienen el monopolio en la postulación de candidaturas de acuerdo con el principio de mayoría relativa, sí la tienen en la postulación de candidaturas según el principio de representación proporcional. La prohibición normativa en el acceso de candidatos independientes a las candidaturas por este principio vulnera el principio de equidad. En ninguna ley electoral se hace explicita la regencia de este principio entre candidatos independientes y de partido, antes, durante y después de la contienda electoral, por lo que debe introducirse en la norma fundamental para que sea exigible la equidad en la competencia electoral. En consecuencia, es necesario que se reforme nuevamente el artículo 54 constitucional y el artículo 362 de la LGIPE, para que las nuevas candidaturas participen en lo cargos públicos que se compiten mediante el principio de representación proporcional.

Finalmente, cabe decir que aunque la independencia de las candidaturas independientes no la asegura el nombre, la práctica política de los candidatos independientes en sus actuales cargos habrá de mostrar si éstos realmente están de parte de los ciudadanos. El debate en los congresos en un futuro inmediato entorno a dichas candidaturas debería versar sobre el establecimiento del requisito de no militancia partidista previa al registro de aspirantes. $\mathrm{Al}$ permitir la norma electoral el registro de aspirantes que renunciaron a sus partidos por no haber recibido la candidatura, hace que estas candidaturas sean proclives a recibir candidatos cuyo perfil no es idóneo para una independencia fáctica de los partidos políticos. Incluso, pueden utilizarse para chantajear a sus correligionarios de partido si no los postulan a un puesto de elección popular.

Los resultados del proceso electoral 2015 indican que los candidatos independientes participaron más a nivel municipal que a nivel estatal o federal. En el ámbito municipal fue donde se presentaron más casos de triunfos electorales de candidatos independientes. Esto es explicable, por un lado, porque 
los cargos a alcalde son los más comunes en México; por el otro, porque a nivel municipal existe un vínculo más estrecho entre los ciudadanos y los candidatos independientes, ya que "el municipio es el espacio más cercano a la ciudadanía". ${ }^{97}$ A nadie es desconocido que el número de habitantes en los municipios es más pequeño que los de un estado, a tal grado que en no pocos de ellos los ciudadanos se conocen entre sí y, en consecuencia, a los candidatos que se postulan por la vía independiente.

${ }^{97}$ Rivera Hernández, Claudia, op. cit., p. 9. 